\title{
Pneumococci causing invasive disease in Britain 1982-1990
}

\author{
G. COLMAN, E. M. COOKE, B. D. COOKSON, P. G. COOPER, A. EFSTRATIOU \\ and R. C. GEORGE \\ Division of Hospital and Respiratory Infection. Central Public Health Laboratory, 61 Colindale Avenue, \\ London NW9 5HT
}

\begin{abstract}
A total of 5348 isolates of Streptococcus pneumoniae was serotyped and screened for insusceptibility to tetracycline, penicillin, erythromycin and chloramphenicol. Of these, $4238(79 \%)$ were isolated from patients who had pneumonia or meningitis or were bacteraemic. Altogether, 3948 (74\%) of the isolates belonged to one or other of the serotypes $1,3,4,6,8,9,14,19$ or 23 with serotypes $6,14,18,19$ and 23 being frequent causes of invasive disease in young children. Many isolates of type 1 were isolated from pneumonia and few from meningitis. Some $768(14 \%)$ isolates were insusceptible to one or more antibiotic and 591 of these belonged to serotypes 6, 9, 14, 19 or 23 . Representatives of type 14 resistant to erythromycin were prominent from 1986 onwards. There was an increase in the number of multi-resistant pneumococci from 1985. Among these were isolates of type 23 insusceptible to penicillin, chloramphenicol and tetracycline and cultures of type 6 resistant additionally to erythromycin.
\end{abstract}

\section{Introduction}

Nearly all clinical isolates of Streptocococcus pneumoniae fall into one or other of 46 serogroups or serotypes based on the antigenicity of their capsular polysaccharides. Twenty-one of these, the serogroups, are each composed of a set of antigenically related strains and can be subdivided further giving a total of 90 type designations [1]. An example of the precision of the method is the modulations within serogroup 15 of type $15 \mathrm{~B}$ to $15 \mathrm{C}$ due to loss of an O-acetyl group [2]. For simplicity, serogroups such as group 23 which is composed of types $23 \mathrm{~F}, 23 \mathrm{~A}$ and $23 \mathrm{~B}$ - will be referred to here as 'type 23 ' as well as those, such as 'type 3 ' which react with a single factor serum [1].

Serotyping has provided a tool for studies of outbreaks. For instance, in the 1644 cases of pneumococcal pneumonia that occurred in an American Air Force Base over three successive winters, one-third were caused by pneumococcus type 2 [3]. Large outbreaks, comparable to that in the Air Force Base are not known to have occurred in Britain. On the other hand pneumococci comprise $11 \%$ of positive blood cultures and $18 \%$ of isolates from bacterial meningitis [4].

Received 6 Jan. 1997; accepted 28 April 1997.

Corresponding author: Dr G. Colman. Present address: 51 Brattle Wood, Sevenoaks, Kent TN13 1QT.
The distribution of serotypes causing disease differs by time, place and age of patient. Type 2, for instance, was one of the predominant types causing disease in Denmark in the years 1939-1947 [5]. It was not found in that country between 1983 and 1988 [6] but it causes invasive infections in Africa [7]. Type 5 is one of the less common serotypes in Europe and North America. For that reason it was not included in the 14-valent pneumococcal vaccine, but it is prevalent in West Africa [8] and was incorporated in the 23-valent vaccine. The apparently invasive type 46 occurs in South Africa [9] and Papua-New Guinea [10], but is not isolated in Europe [5,6] or Australia [11]. Among children, serotypes 6, 14, 19 and 23 account for many infections. In Alabama, for instance, over a 15-year period they caused nearly two-thirds of the pneumococcal infections in infants and young children [12].

Insuceptibility to one or more clinically useful antibiotics has been described in representatives of all common types [13]. Worldwide, the problem strains are found most often in serotypes 6,14, 19 or 23 . Disparate levels of susceptibility to penicillin were detected in the very first tests in $1941[14,15]$. Resistance became a clinical problem with the finding of insusceptiblity to tetracycline in 1963 [16], penicillin in 1967 [17], erythromycin and lincomycin in 1967 [18], chloramphenicol in 1970 [19] and multiple resistance - that is resistance to three or 
more classes of antibiotics - in 1977 [20]. In an earlier survey of pneumococci isolated in Britain from invasive disease, resistance to antibiotics was not a major problem [21].

The results presented here are from routine surveillance based upon isolates referred from hospital and public health laboratories in England and Wales. The aims were to follow the distribution of types among isolates causing invasive disease, investigate possible outbreaks of infection and screen isolates for insusceptibility to antibiotics. There was thus a deliberate bias towards the study of isolates of clinical importance. Additional information on pneumococcal infection is available to the Public Health Laboratory Service from laboratory reports to the Communicable Disease Surveillance Centre and also from special surveys [22].

The period beginning in 1982 has been chosen for this report because, apart from special surveys, less information was available from earlier years and techniques were being modified. For example, when screening for insusceptibility to erythromycin was begun in 1979, disks with a content of $0.125 \mu \mathrm{g}$ of this antibiotic were used. Later, a change was made to disks containing erythromycin $0.5 \mu \mathrm{g}$ because of the small zone size obtained with susceptible strains with the disks of lower content.

\section{Materials and methods}

\section{Isolates}

Results from 5348 isolates were used (Table 1). Records for which the referring laboratory had not given both the patient's name and the source of the culture were excluded. If more than one isolate of a single serotype was available from either one episode of infection or from what appeared to be hospital or family spread then an arbitrary choice was made of a single record. For example, an isolate from cerebrospinal fluid (CSF) would be chosen rather than one from blood culture on the same patient. Occasionally, isolates of different serotypes were isolated at different times from invasive disease affecting an individual patient and these were accepted as re-infections.

The cultures that form the basis of Table 1 can be divided into those from sites that are normally sterile and those from the vagina, urinary tract, wounds (including burns), eyes, ears, sputum or nasal swabs where pathogenicity cannot be assumed. The isolates classed as coming from patients with pneumonia were from blood cultures of patients with this clinical diagnosis or were isolated from pleural aspirates, lung tissue or pericardial fluid. Those from meningitis were from CSF, blood or both. Bacteraemia isolates were from patients with positive blood cultures for whom clinical diagnoses were either not supplied or in whom

Table 1. Sources of 5348 isolates of pneumococci sent to the Streptococcus Reference Unit, 1982-1990

\begin{tabular}{|c|c|c|c|c|c|c|c|c|c|c|}
\hline \multirow[b]{2}{*}{ Source } & \multicolumn{10}{|c|}{ Year } \\
\hline & 1982 & 1983 & 1984 & 1985 & 1986 & 1987 & 1988 & 1989 & 1990 & Total \\
\hline \multirow[t]{2}{*}{ Pneumonia } & $270^{*}$ & 146 & 163 & 130 & 187 & 186 & 265 & 266 & 283 & 1896 \\
\hline & 23 & 7 & 10 & 8 & 13 & 15 & 26 & 18 & 22 & 142 \\
\hline \multirow[t]{2}{*}{ Bacteraemia } & 75 & 117 & 139 & 126 & 139 & 128 & 154 & 228 & 223 & 1329 \\
\hline & 4 & 8 & 5 & 9 & 14 & 5 & 21 & 25 & 35 & 126 \\
\hline \multirow[t]{2}{*}{ Meningitis } & 72 & 75 & 109 & 97 & 121 & 115 & 143 & 134 & 147 & 1013 \\
\hline & 2 & 0 & 3 & 6 & 7 & 11 & 7 & 8 & 19 & 63 \\
\hline \multirow[t]{2}{*}{ Arthritis or osteomyelitis } & 5 & 4 & 9 & 4 & 6 & 5 & 9 & 3 & 9 & 54 \\
\hline & 0 & 0 & 0 & 0 & 1 & 0 & 2 & 1 & 1 & 5 \\
\hline \multirow[t]{2}{*}{ Endocarditis } & 2 & 2 & 5 & 1 & 3 & 3 & 3 & 2 & 3 & 24 \\
\hline & 0 & 0 & 0 & 0 & 0 & 0 & 1 & 0 & 1 & 2 \\
\hline \multirow[t]{2}{*}{ Cellulitis } & 5 & 4 & 4 & 2 & 4 & 6 & 4 & 7 & 13 & 49 \\
\hline & 1 & 2 & 1 & 0 & 0 & 0 & 0 & 1 & 3 & 8 \\
\hline \multirow{2}{*}{ Abdominal infection } & 5 & 6 & 8 & 1 & 4 & 2 & 4 & 9 & 9 & 48 \\
\hline & 1 & 0 & 0 & 0 & 0 & 0 & 0 & 1 & 0 & 2 \\
\hline \multirow[t]{2}{*}{ Neonatal sepsis } & 0 & 3 & 4 & 2 & 6 & 5 & 8 & 11 & 9 & 48 \\
\hline & 0 & 0 & 0 & 0 & 2 & 0 & 2 & 0 & 1 & 5 \\
\hline \multirow[t]{2}{*}{ Vagina } & 0 & 4 & 2 & 3 & 8 & 8 & 5 & 5 & 4 & 39 \\
\hline & 0 & 1 & 0 & 0 & 1 & 0 & 0 & 1 & 2 & 5 \\
\hline \multirow[t]{2}{*}{ Urinary tract } & 3 & 0 & 1 & 2 & 4 & 2 & 3 & 2 & 0 & 17 \\
\hline & 0 & 0 & 0 & 0 & 0 & 0 & 0 & 0 & 0 & 0 \\
\hline \multirow[t]{2}{*}{ Wounds } & 1 & 0 & 0 & 6 & 1 & 0 & 10 & 4 & 2 & 24 \\
\hline & 1 & 0 & 0 & 1 & 0 & 0 & 0 & 1 & 0 & 3 \\
\hline \multirow[t]{2}{*}{ Eye } & 3 & 7 & 12 & 16 & 14 & 10 & 18 & 37 & 25 & 142 \\
\hline & 0 & 1 & 0 & 2 & 1 & 4 & 8 & 11 & 18 & 45 \\
\hline \multirow[t]{2}{*}{ Ear } & 6 & 8 & 8 & 4 & 8 & 8 & 11 & 11 & 20 & 84 \\
\hline & 0 & 1 & 0 & 1 & 2 & 2 & 3 & 4 & 13 & 26 \\
\hline \multirow[t]{2}{*}{ Sputum or nasal swabs } & 71 & 29 & 11 & 20 & 45 & 74 & 92 & 81 & 158 & 581 \\
\hline & 12 & 7 & 9 & 16 & 28 & 53 & 46 & 53 & 112 & 336 \\
\hline \multirow[t]{2}{*}{ Total } & 518 & 405 & 475 & 414 & 550 & 552 & 729 & 800 & 905 & 5348 \\
\hline & 44 & 27 & 28 & 43 & 69 & 90 & 116 & 124 & 227 & 768 \\
\hline
\end{tabular}

*Total from this condition with number insusceptible to one or more antimicrobial agent given below. 
there was no evidence of localisation. For arthritis or osteomyelitis, pneumococci were isolated from blood culture, joint fluid or bone tissue. Endocarditis strains were solely from blood cultures. Isolates from cellulitis - including orbital cellulitis and epiglottitis - and peritonitis were isolated from either blood culture or tissue fluid or both. The category neonatal sepsis was restricted to organisms isolated from the blood or CSF or neonates for whom a strain of the same serotype was isolated from the genital tract of the mother. Nearly all the isolates from eyes were from conjunctival or corneal swabs. The exceptions were two from endophthalmitis. Two cultures only were from middle ear fluid, all other in this category were from ear swabs.

\section{Identification}

On reception isolates were cultured on horse blood agar incubated in air supplemented with $\mathrm{CO}_{2}(5 \% \mathrm{v} / \mathrm{v})$. If cultures were thought to be mixed further subcultures were made. Nearly all pneumococci isolated from invasive disease are susceptible to optochin (ethylhydrocuprein), are lysed by bile or other detergents (activation of $\mathrm{N}$-acetylmuramic acid, L-alanine amidase) and are agglutinated by one or other of the currently available typing sera. Exceptions occur: pneumococci can develop resistance to optochin and non-capsulate pneumococci may not be bile-soluble [23]. Conversely, occasional isolates that clearly are not pneumococci are bile soluble. An example is isolate R985, Streptococcus suis, serological group R [24]. Finally, cross-reactions between various oral streptococci and pneumococcal serotypes have been documented [25].

Optochin susceptibility and serotyping were used routinely. Disks containing optochin $5 \mu \mathrm{g}$ (Mast Laboratories, Bootle, Merseyside) were applied to blood agar and zone sizes $>12 \mathrm{~mm}$ were expected. Isolates that could not be serotyped were tested for bile solubility.

\section{Typing}

Sera for typing were bought from the State Serum Institute, Copenhagen. Routinely, the pooled sera A-I and the individual sera 1-48, excepting the numbers 26 and 30 , were employed [26]. Isolates were subcultured in serum glucose infusion broth. The bacterial growth was deposited by centrifugation, resuspended in a few drops of the supernate and tested for agglutination in, first, the pooled sera, then the components of the pool agglutinating the isolate. Typing with factor sera, as used by Smart [27], was not done. Isolates that did not react with any of the pools were tested for agglutination with polyvalent 'OMNI-serum'. If agglutinated by that reagent the procedure with individual pools and sera was repeated. If not, bile solubility was determined.
Until 1981 isolates were serotyped by two methods, namely agglutination and the capsular swelling reaction. The same result was obtained by either method and the simpler agglutination procedure was adopted for routine use. Both methods are used during production of typing sera [28].

\section{Susceptibility to antibiotics}

A cotton wool swab was used to transfer growth from the initial culture to a second horse blood agar plate (Blood Agar Base supplemented with Yeast Extract $0.3 \% \mathrm{w} / \mathrm{v}$; Oxoid) and disks (Oxoid) were applied. The agents used are listed, followed first by the drug content of each disk, second the zone size obtained with most susceptible strains and third the critical zone size used to define insusceptible strains. They were optochin: $5 \mu \mathrm{g},>12 \mathrm{~mm}, \leqslant 9 \mathrm{~mm}$; oxacillin: $1 \mu \mathrm{g},>20 \mathrm{~mm}, \leqslant 15 \mathrm{~mm}$; benzylpenicillin: $0.6 \mu \mathrm{g}$, $>25 \mathrm{~mm}, \leqslant 25 \mathrm{~mm}$; tetracycline: $5 \mu \mathrm{g},>20 \mathrm{~mm}$, $\leqslant 18 \mathrm{~mm}$; erythromycin: $0.5 \mu \mathrm{g},>14 \mathrm{~mm}, \leqslant 14 \mathrm{~mm}$; chloramphenicol: $10 \mu \mathrm{g},>20 \mathrm{~mm}, \leqslant 15 \mathrm{~mm}$. All came within the description 'low content' as used by Snell and colleagues [29]. A reduction in zone size about the oxacillin disk was used to indicate insusceptibility to penicillin [30]. The methods used would not distinguish between moderate- and high-level resistance and the term 'insusceptible' will be used for both.

\section{Results and Discussion}

\section{Type distribution - general}

The serotype distribution of the cultures is given in Table 2; $3693(69 \%)$ fell into one or other of nine serotypes, each of which represented at least $5 \%$ of the strains studied. They were serotypes $1,3,4,6,8,9,14$, 19 and 23 . Another nine serotypes $-7,10,11,12,15$, $17,18,22$ and 33 - each accounted for $1-5 \%$ of the total. This distribution of most frequent types did not differ greatly from those recorded in Denmark [6] or Australia [11], although types 7 and 12 were relatively more common in the former study and 7 and 18 in the latter. There were few isolates of 22 serotypes, including types 2 and 5 (Table 2). No isolates of serotypes $40,43,44,45,46$ or 47 were received. There were no obvious trends in the distribution of serotypes from laboratories that referred isolates over several years.

\section{Age}

Of the total of 5348 isolates, $4238(79 \%)$ were from patients who had pneumonia, meningitis or were bacteraemic (Table 1). Pneumococcal meningitis or bacteraemia tended to occur more often in younger persons than pneumococcal pneumonia. The ages of 2936 patients were available for the years 1986-1990. This was $83 \%$ of the total of 3536 patients for those years. Of these, 2257 belonged to one or other of 
Table 2. Serotype, source of isolates and number insusceptibile

\begin{tabular}{|c|c|c|c|c|c|c|c|}
\hline \multirow[b]{2}{*}{ Serotype } & \multicolumn{7}{|c|}{ Source } \\
\hline & $\begin{array}{l}\text { Pneumonia, } \\
\text { empyema }\end{array}$ & $\begin{array}{c}\text { Meningitis, } \\
\text { brain } \\
\text { abscess }\end{array}$ & Bacteraemia & $\begin{array}{l}\text { Other } \\
\text { invasive } \\
\text { states* }\end{array}$ & $\begin{array}{l}\text { Infections: } \\
\text { possible } \\
\text { pathogens } \dagger\end{array}$ & $\begin{array}{c}\text { Sputum, } \\
\text { nasal } \\
\text { swabs }\end{array}$ & Total \\
\hline \multirow[t]{2}{*}{1} & $208 \ddagger$ & 13 & 83 & 30 & 7 & 7 & 348 \\
\hline & 18 & 0 & 3 & 0 & 1 & 0 & 22 \\
\hline \multirow[t]{2}{*}{3} & 264 & 61 & 120 & 21 & 41 & 45 & 552 \\
\hline & 5 & 3 & 6 & 0 & 2 & 9 & 25 \\
\hline \multirow[t]{2}{*}{4} & 124 & 43 & 81 & 11 & 7 & 6 & 272 \\
\hline & 1 & 1 & 3 & 0 & 0 & 1 & 6 \\
\hline \multirow[t]{2}{*}{6} & 98 & 127 & 112 & 15 & 49 & 111 & 512 \\
\hline & 5 & 10 & 11 & 3 & 21 & 84 & 134 \\
\hline \multirow[t]{2}{*}{7} & 96 & 56 & 48 & 4 & 5 & 16 & 225 \\
\hline & 1 & 0 & 0 & 2 & 1 & 5 & 9 \\
\hline \multirow[t]{2}{*}{8} & 143 & 44 & 50 & 7 & 8 & 3 & 255 \\
\hline & 4 & 2 & 0 & 1 & 1 & 0 & 8 \\
\hline \multirow[t]{2}{*}{9} & 138 & 63 & 112 & 6 & 17 & 30 & 366 \\
\hline & 7 & 1 & 5 & 1 & 8 & 16 & 38 \\
\hline \multirow{2}{*}{10} & 19 & 25 & 10 & 2 & 2 & 11 & 69 \\
\hline & 2 & 0 & 1 & 1 & 0 & 3 & 7 \\
\hline \multirow[t]{2}{*}{11} & 43 & 12 & 25 & 5 & 7 & 18 & 110 \\
\hline & 1 & 0 & 0 & 1 & 0 & 6 & 8 \\
\hline \multirow[t]{2}{*}{12} & 28 & 25 & 27 & 6 & 1 & 2 & 89 \\
\hline & 1 & 0 & 0 & 1 & 0 & 0 & 2 \\
\hline \multirow[t]{2}{*}{14} & 288 & 137 & 205 & 26 & 29 & 45 & 730 \\
\hline & 60 & 32 & 57 & 5 & 14 & 30 & 198 \\
\hline \multirow[t]{2}{*}{15} & 21 & 26 & 19 & 4 & 4 & 13 & 87 \\
\hline & 3 & 2 & 2 & 0 & 1 & 4 & 12 \\
\hline \multirow[t]{2}{*}{17} & 14 & 15 & 13 & 2 & 3 & 6 & 53 \\
\hline & 1 & 1 & 1 & 0 & 0 & 0 & 3 \\
\hline \multirow[t]{2}{*}{18} & 45 & 77 & 80 & 10 & 6 & 13 & 231 \\
\hline & 3 & 0 & 3 & 0 & 0 & 3 & 9 \\
\hline \multirow[t]{2}{*}{19} & 128 & 91 & 114 & 25 & 39 & 54 & 451 \\
\hline & 10 & 5 & 9 & 1 & 5 & 27 & 57 \\
\hline \multirow[t]{2}{*}{22} & 33 & 21 & 33 & 10 & 4 & 3 & 104 \\
\hline & 1 & 0 & 0 & 0 & 1 & 0 & 2 \\
\hline \multirow[t]{2}{*}{23} & 83 & 86 & 86 & 21 & 37 & 149 & 462 \\
\hline & 9 & 3 & 11 & 3 & 18 & 130 & 174 \\
\hline \multirow[t]{2}{*}{33} & 27 & 20 & 19 & 3 & 8 & 8 & 85 \\
\hline & 1 & 1 & 1 & 0 & 0 & 3 & 6 \\
\hline \multirow[t]{2}{*}{ Others $\$$} & 96 & 71 & 92 & 15 & 32 & 41 & 347 \\
\hline & 9 & 2 & 13 & 3 & 6 & 15 & 48 \\
\hline \multirow[t]{2}{*}{ Total } & 1896 & 1013 & 1329 & 223 & 306 & 581 & 5348 \\
\hline & 142 & 63 & 126 & 22 & 79 & 336 & 768 \\
\hline
\end{tabular}

*Isolates from arthritis, endocarditis, osteomyelitis, cellulitis, neonatal septicaemia and peritonitis.

$\dagger$ Organisms isolated, usually not in pure culture, from wounds, eye or ear swabs, the vagina or urinary tract.

\$Total of this serotype with number insusceptible to one or more antimicrobial agent below.

${ }^{8}$ Serotypes with 1-48 representatives brought together here. They are, with the number susceptible to one or more antibiotic in parentheses: 2 , $1(0) ; 5,39(17) ; 13,14(2) ; 16,23(0) ; 20,48(1) ; 21,10(2) ; 24,23(1) ; 25,2(2) ; 27,7(0) ; 28,3(0) ; 29,14(1) ; 31,18(1) ; 32,4(1) ; 34,26(0) ; 35$, $16(5) ; 362(0) ; 37,6(0) ; 38,14(2) ; 39,14(0) ; 41,3(0) ; 42,5(2) ; 48,2(0) ; 29+35,1(0) ; 35+42,4(0)$; non-typable, 48(11). No isolates of serotypes $40,43,44,45,46$ or 47 were handled.

the three main disease categories. More than onethird with meningitis $(38 \%)$ or bacteraemia $(35 \%)$ were aged $\leqslant 5$ years. For a diagnosis of pneumonia only $6 \%$ were aged $\leqslant 5$ years and $66 \%$ were $>60$ years.

A comparison was made of the serotype distribution between, on the one hand, those aged $\leqslant 5$ years and, on the other, older children or adults (Table 3). Among isolates from invasive disease, representatives of serotypes $6,14,18,19$ and 23 were more common in young children. The same five together with type 4 caused most cases of systemic infection in children in Australia [11]. Some serotypes, in particular types 11 and 15, have been isolated more often in carriage studies on children than from invasive disease [21,
31]. In contrast to the findings in young children, isolates of serotypes $3,8,11,12,17$ and 22 were relatively more common in those aged $\geqslant 6$ years (Table 3).

For the strains of types $1,3,8,14,18$ and 23 that are included in Table 3 the distribution by age of patient, in 10-year bands, is shown in Fig. 1. The general increase, with age, of types 3 and 8 , and the predominance of type 18 in children is evident. Something like a bimodal distribution occurred with types 14 and 23 . Type 1 is illustrated because percentages were relatively evenly distributed by age. Of the total of 309 isolates of these six serotypes from children aged $<10$ years of age, only 22 were isolated from those aged 6-9 years. 
Table 3. Isolates received from 2936 patients of known age, 1986-1990

\begin{tabular}{|c|c|c|c|c|c|}
\hline \multirow[b]{2}{*}{ Type } & \multicolumn{2}{|c|}{$\geqslant 6$ years of age } & \multicolumn{2}{|c|}{$\leqslant 5$ years of age } & \multirow[b]{2}{*}{ Total } \\
\hline & Invasive & Non-invasive & Invasive & Non-invasive & \\
\hline 1 & $171(9.2)^{*}$ & 8 & $32(5.6)$ & 4 & 215 \\
\hline 3 & 207 (11.1) & 22 & $17(3.0 \dagger)$ & 14 & 260 \\
\hline 4 & $126(6.8)$ & 5 & $22(3.8)$ & 1 & 154 \\
\hline 6 & $106(5.7)$ & 51 & 99 (17.2 $)$ & 50 & 306 \\
\hline 7 & $88(4.7)$ & 2 & $17(3.0)$ & 3 & 110 \\
\hline 8 & $111(6.0)$ & 3 & $2(0.3)$ & 1 & 117 \\
\hline 9 & $173(9.3)$ & 19 & $29(5.0)$ & 11 & 232 \\
\hline 10 & $23(1.2)$ & 3 & $4(0.7)$ & 1 & 31 \\
\hline 11 & $39(2.1)$ & 5 & $1(0.2)$ & 5 & 50 \\
\hline 12 & $43(2.3)$ & 2 & $3(0.5)$ & 1 & 49 \\
\hline 14 & $270(14.5)$ & 22 & $147(25.5)$ & 25 & 464 \\
\hline 15 & $27(1.5)$ & 7 & $7(1.2)$ & 4 & 45 \\
\hline 17 & $25(1.3)$ & 2 & $3(0.5)$ & 0 & 30 \\
\hline 18 & $49(2.6)$ & 5 & $52(9.0)$ & 0 & 106 \\
\hline 19 & $118(6.3)$ & 25 & $74(\mathbf{1 2 . 8})$ & 33 & 250 \\
\hline 22 & $47(2.5)$ & 0 & $2(0.3)$ & 3 & 52 \\
\hline 23 & $103(5.5)$ & 82 & $37(6.4)$ & 46 & 268 \\
\hline 33 & $34(1.8)$ & 6 & $8(1.4)$ & 1 & 49 \\
\hline Others ${ }^{\S}$ & $102(5.5)$ & 24 & $20(3.5)$ & 2 & 148 \\
\hline Total & 1862 & 293 & 576 & 205 & 2936 \\
\hline
\end{tabular}

${ }^{*}$ Total of this serotype and for invasive isolates percentages in that age group in parentheses.

†Italics indicate percentages one-half, or less, of the percentage from patients aged $\geqslant 6$ years

$\ddagger$ Bold type used for a percentage more than double the percentage from patients aged $\geqslant 6$ years

${ }^{8}$ All types with from 1 to 23 representatives brought together here. It is composed of serotypes, $5,13,16,20,21,24,27,29,31,32,34,35$, $37,38,41,35+42$ and non-typable isolates.

Scott [32] has brought together the results of studies performed in different countries. He calculated the relative risk of invasive disease caused by type 1 and found that it declined throughout life. Most of his data on type 1 were from studies in Brazil. In one of these sets [33] only two isolates of type 1 were from patients aged $\geqslant 50$ years. In contrast, $86(42 \%)$ of the 203 isolates of type 1 included in Fig. 1 were from patients aged $\geqslant 50$ years.

\section{Pneumonia}

Altogether, $1896(35 \%)$ of the isolates were isolated from patients with pneumonia (Table 1). The distribution of serotypes may be different in patients

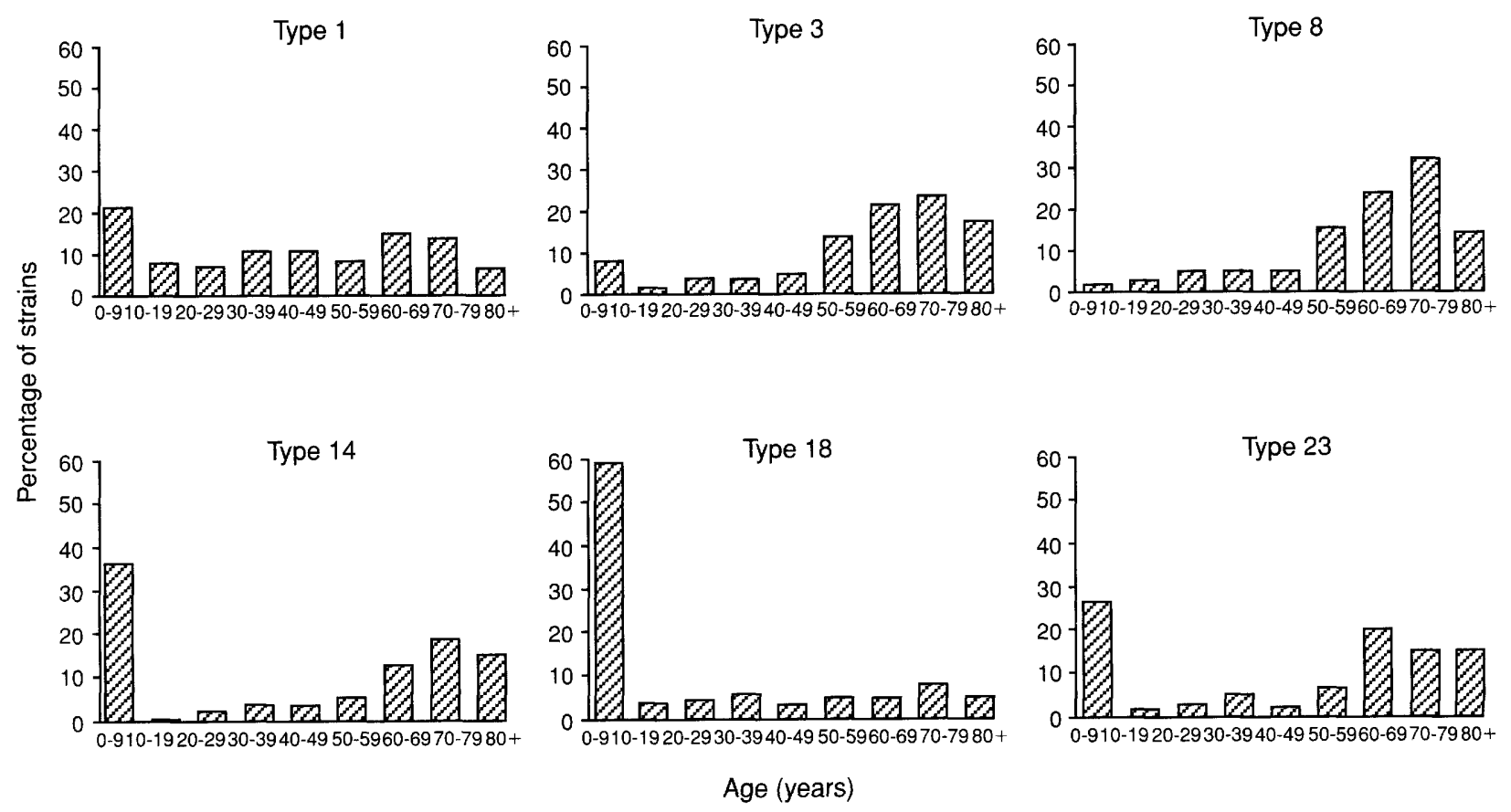

Fig. 1. Serotype of pneumococcus and age distribution, in 10-year bands, among 1198 patients with invasive infection. Number of cases: type 1, 203 (60\% males); 3, 224 (62\% males); 8, 113 (62\% males); 14, 417 (52\% males); 18,101 (57\% males); 23,140 (60\% males). 
with pneumococcal pneumonia but negative blood cultures. Of the isolates causing pneumonia types 1,3 and 14 each contributed at least $10 \%$ of the total (Table 2). Type 1 was unique because it had the largest proportion (208 of 348 isolates; 60\%) from pneumonia and the smallest (only 13;4\%) from meningitis. This association of type 1 with pneumonia and infrequency in meningitis has been noted by others $[6,11]$. An outbreak of bacteraemic pneumonia caused by type 1 pneumococci occurred among Australian aborigines [34]. As in other outbreaks, carriage of type 1 strains was uncommon unless the subject had invasive disease or was in contact with cases of acute infection.

The susceptibility of AIDS patients to pneumococcal infection is indicated by the frequency of pneumococcal pneumonia in them, the many such infections that are bacteraemic and the number of recurrences of infection [35]. The first cultures handled, four in all, from patients recorded as being infected with HIV were referred in 1986. Since then, cultures from HIVinfected patients comprised one from an infant with fatal septicaemia and six isolates from five individuals with chest infections. All five cultures handled in 1986 and 1987 were susceptible to antibiotics. The isolate received in 1989 was resistant to tetracycline, but four of the five isolates received in 1990 were insusceptible to penicillin, tetracycline and either chloramphenicol or erythromycin.

\section{Bacteraemia}

The clinical states seen in pneumococcal bacteraemia range from a passing febrile illness in which recovery occurs without treatment [36] to an acute septicaemic illness. Of the 1329 cultures from bacteraemias there were 205 of type $14(15 \%$ of the total), followed by types 3,6,9 and 19 - each about $9 \%$ of the total (Table 2). Among individual serotypes, $80(35 \%)$ of 231 of the cultures of type 18 were from bacteraemias; a smaller total but a larger proportion.

In adults, pneumococcal bacteraemia is often associated with a pre-disposing condition [37], one of which is splenectomy [38], and another is splenic dysfunction [39]. Twenty patients were known to have had previous splenectomy and of these nine presented with meningitis, eight with septicaemia, two with pneumonia and one with a post-surgical abscess. Strains of type 23 were isolated from five patients; types $9,18,19,24$ and 33 were each isolated from two subjects; and single cultures of types 11, 20, 22, 38 and 42 were handled. Two patients, one infected with type 9 , the other with type 19 , had received the pneumococcal vaccine.

During the years 1982-1992 there were reports to the Public Health Laboratory Service, Communicable
Disease Surveillance Centre, London (CDSC) of 11299 isolations of $S$. pneumoniae from blood cultures. The overall rate of pneumococcal bacteraemia in males exceeded that in females by $26 \%$. During this period the proportion of infections at the extremes of age - those aged $\leqslant 1$ year and those $>75$ years - rose three-fold [4].

\section{Meningitis}

From 1982 to 1992,3500 cases of pneumococcal meningitis were reported to CDSC and 1023 (29\%) were in infants aged $\leqslant 1$ year. For both meningitis and bacteraemia the first week of life is the time of greatest risk for babies [4].

An unknown proportion of the 1013 cultures handled by us from meningitis, $19 \%$ of all cultures, would have been included in the CDSC figures. The largest number of isolates from meningitis $(137 ; 14 \%)$ were, again, of type 14 . Serotypes with the largest proportion of isolates from meningitis were type 10 (25 of 69 isolates; $36 \%$ ), type 18 (77 of 231 isolates; 33\%) and type 15 (26 of 87 isolates; 30\%). Only 13 of 348 cultures of type $1(4 \%)$ were from meningitis. This comparative rarity of type 1 has been noted in an earlier survey in this country [40]. However, type 1 was the most common cause of meningitis in West Africa [8], while in Denmark from 1947 to 1962 types 1,3 and 7 were common in adults with meningitis and types 4, 6 and 18 in children [41]. In South Africa, for the years 1979-1986, types 1, 6, 14 and 19 were the most numerous isolates from pneumococcal meningitis [7].

There were 24 patients with recurrent meningitis and among these, a head injury had been recorded for 14 patients. The set of 24 cultures was composed of five representatives of type 6 , three of type 23 , two each of types $10,14,15,19$ and 33 together with single isolates of types $8,9,20,34,39$ and a non-typable isolate.

\section{Vaccine}

The current pneumococcal vaccine contains 23 capsular polysaccharides. A total of 5001 isolates, forming the body of Table 2 , belonged to 18 of the serotypes or serogroups numbered between 1 and 33. They represented $93.5 \%$ of the isolates studied and all are incorporated in this vaccine. Because of the lack of cross-protection within each of the serogroups 9 and 19 , capsular polysaccharides from serotypes $9 \mathrm{~N}, 9 \mathrm{~V}$, $19 \mathrm{~F}$ and 19A are used in the vaccine. The remaining three components of the vaccine, serotypes 2, 5 and 20 , are at present uncommon in this country. They are listed in a footnote to Table 2 and comprised $1.6 \%$ of the isolates studied.

In a randomised trial among young African gold- 
miners, immunisation with pneumococcal polysaccharide gave c. $80 \%$ protection against bacteraemic infection caused by a serotype present in the vaccine [42]. By studying the distribution of serotypes causing infection among immunised and non-immunised populations, indirect cohort analysis, similar levels of protection appear likely in elderly subjects who are immunocompetent [43]. In contrast, little or no protection could be detected in, for example, patients with sickle cell disease, leukaemia or multiple myeloma [43, 44]. Among children with sickle cell disease, penicillin prophylaxis has protected against pneumococcal septicaemia $[39,44]$.

An additional problem is the poor response of young children to some polysaccharides. To provide protection for them, conjugate immunogens of the serotypes $6 \mathrm{~B}, 14,19 \mathrm{~F}$ and $23 \mathrm{~F}$ have been suggested with the possible later addition of types 4,9 and 18 [45]. These seven serotypes comprised $78 \%$ of isolates from invasive disease in young children (Table 3).

\section{Arthritis or osteomyelitis}

Isolates were received from 44 cases of septic arthritis. The ages of 27 of these patients were available and eight were aged $\leqslant 2$ years: the next four were aged 10 , 32,45 and 51 years. Four of the 44 were infected at the same time at more than one site, two with polyarthritis. Previous meningitis was recorded for one patient. Before antibiotics were available infections involving more than one site were apparently common [46]. The 44 isolates from arthritis were distributed across 14 serotypes including: type 14 (eight isolates), types 4 and 22 (five isolates each) and types 1, 6 and 19 (four isolates each).

In one series of cases of pneumonoccal osteomyelitis [46] strains of serotype 19 were unusually common, comprising four of the 11 isolates. The same serotype, five of 10 referrals, was predominant among our isolates from this infection.

\section{Abdominal infection}

Pneumococcal peritonitis can follow conditions such as appendicitis [47], liver failure or bacteraemia. Primary pneuomococcal peritonitis occurs, albeit infrequently, in young girls [48]. The infection has occurred in women fitted with intra-uterine contraceptive devices [49] and the infection has been produced experimentally by the introduction of the organism into the vagina of monkeys [50].

Some 48 isolates were received from patients with abdominal infections and they belonged to one or other of 13 serotypes with 16 isolates in type 1 , seven in type 3 and five in type 14. The referring laboratories described 10 of the isolates as coming from patients with primary peritonitis, all but one of whom were female. In contrast, the six isolates from appendicitis were distributed equally between types 6, 14 and 19 and only one patient was female.

\section{Endocarditis}

The recognised suppurative complications of bacteraemic pneumococcal pneumonia include meningitis, empyema, endocarditis and less often arthritis or peritonitis [51], 24 isolates of 16 serotypes were received from patients with endocarditis, an unknown proportion of whom had had pneumonia. Types 14 (four isolates) and types 6 and 23 (three isolates each) were the most numerous.

\section{Cellulitis}

There were 49 isolates in the collection from patients with cellulitis and for 13 of these periorbital cellulitis was specified. Other conditions included epiglottitis, necrotising fasciitis, blistering cellulitis and cellulitis surrounding a burn. Altogether, 21 different serotypes were represented, including type 23 (eight isolates), type 14 (seven isolates) types 3 and 19 (five isolates each) and type 18 (four isolates). At least nine of the periorbital infections occurred in children and among the pneumococci recovered from this condition there were three isolates each of types 14 and 18, and two each of types 19 and 23.

\section{Neonatal septicaemia}

Pneumococci have been reported as causing $2-10 \%$ of cases of neonatal sepsis [52]. Isolates were received from 48 neonatal infections in which cultures of the same serotype were isolated from vaginal swabs of the mother and blood cultures or CSF of the baby. The isolates were distributed between 18 serotypes, with seven representatives in each of types 1 and 19, six of type 23 , five of type 3 , three each of types $6,8,18$ and 27 , two of type 4 and one each of types $5,9,11,12$, $14,15,20,22$ and 24.

The organism is isolated infrequently from vaginal swabs [53]: only 39 cultures in this study were exclusively from the site. Some of these cultures were presumably saprophytic, but most were associated with vaginitis, infection of Bartholin's glands or endometritis. The finding of neonatal septicaemia caused by an organism that is not often found in the vagina has been attributed to invasiveness.

\section{Wound infections}

Pneumococci are one of the less common causes of wound infection [11]. Of the 24 isolates from wound pus, nine were from infected burns. The set was composed of 13 serotypes but 13 isolates belonged to one or other of the serotypes $3,14,19$ or 23 . 


\section{Conjunctivitis}

There can be problems in the identification of some pneumococci, or pneumococcus-like streptococci, associated with conjunctivitis [54]. In a study covering selected years from 1935 to 1974, Finland and Barnes [55] found that one-quarter of the strains from eyes were untypable: their largest source of non-typable strains. Similarly in a study in this country [56] all strains from invasive disease could be serotyped, but $2 \%$ of strains from sputum or the nasopharynx and $12 \%$ of strains from eyes could not be serotyped.

Of the 142 isolates from eyes (Table 1) 14 were untypable, usually because growth in broth was granular. In 1985 cultures were received from 24 adolescents affected in a school outbreak of conjunctivitis. Seventeen of these cultures could not be serotyped, five were of type 33 and two of type 34 . One record from each category was used here.

\section{Ear Swabs}

Unlike isolates from the eyes, all 84 cultures from the ears could be serotyped. Of the 84 cultures, 16 were of type 3,13 of type 6,11 of type 14,10 of type 19 , nine of type 7 and five of type 23 . The same six serotypes were dominant also in Orange and Gray's set of 228 strains from otitis media [12]. There were two important differences. First, the latter strains were all isolated from fluid collected after tympanocentesis, ours with two exceptions were from ear swabs, and second, type 3 was fifth in their rank order.

Included in this category were five isolates from infections of the mastoid. They comprised two strains of type 14 and one each of types 3, 9 and 22. When otitis media or mastoiditis led to meningitis the cultures were placed in that category.

In one study middle ear infections accounted for $1.5 \%$ of all visits to general practitioners [57]. S. pneumoniae and Haemophilus influenzae are the predominant primary pathogens in acute otitis media and aspects of such infection caused by pneumococci have been reviewed by others [45].

\section{Sputum or nasal swabs}

Isolates from sputum or nasal swabs were the fourth largest category (Table 1). That 336 of 581 such cultures $(58 \%)$ were insusceptible to one or more antibiotics provides a clear indication of the reason for referral of these isolates. Many were representatives of types 6,14 or 23 (Table 2).

The most prevalent pneumococcal serotypes in the upper respiratory tract are not the same as those isolated from invasive disease [58]. The upper respiratory tract is a reservoir of antibiotic-resistant pneumococci [59].

\section{Insusceptibility to antibiotics}

There were 768 isolates insusceptible to one or other, or any combination, of the antibiotics pencillin, tetracycline, erythromycin or chloramphenicol (Table 1) with a general increase in prevalence through the study period. Altogether $591(77 \%)$ of the 768 isolates belonged to one or other of five serotypes, namely 6,9 , 14, 19 or 23 (Table 2). This clustering was most noticeable in the years 1989 and 1990, when representatives of these serotypes made up $86 \%$ and $87 \%$, respectively, of the insusceptible strains.

Optochin. Optochin has not been used clinically for many years, but the occurrence of resistance to this compound among pneumococci could lead to misidentification of clinical isolates. Mixed populations, susceptible and resistant to optochin, have been observed in fresh clinical isolates of types 3 and 6 [60].

Resistance to optochin was detected in 23 isolates distributed among 15 serotypes. All exhibited the colony forms expected of pneumococci. If the organism was resistant to optochin alone it is not included among the resistant isolates in the tables. Sixteen isolates were obtained in pure culture from invasive disease; there were four representatives of type 6 and three of type 3. In 1985 two cultures of type 3 were collected from throat swabs taken in one incident - one was insusceptible to optochin and tetracycline, the other to tetracycline alone. Again, in 1990 , of two isolates of type 9 , this time from sputum samples from a single patient, one was insusceptible to penicillin and the other to optochin and penicillin.

Tetracycline, chloramphenicol. Insusceptibility to tetracycline was found alone or in combination in 444 (8\% of all isolates) (Table 4). Of these, 116 were insusceptible to tetracycline alone and they were distributed among 23 serotypes. Some 69 of these $116(59 \%)$ were other than the serotypes $6,9,14,19$ or 23 and included the only resistant isolates of the serotypes $24,25,31$ or 42 . The serotypes 1 and 3 accounted for 16 and 11 isolates, respectively.

Insusceptibility to chloramphenicol alone was detected in six isolates and combined with tetracycline in a further 25 isolates. Although isolates of type 5 were uncommon, this serotype contained the highest proportion of isolates insusceptible to antibiotics: 17 of 39 isolates (Table 2). Of these 17, all of which were isolated from invasive disease, eight were insusceptible to tetracycline alone, three to chloramphenicol and six to both chloramphenicol and tetracycline.

Spread of tetracycline-resistant pneumococci in a British hospital was seen first in Liverpool in 1963 [61] and by 1968 almost one-quarter of the pneumococci isolated in the Liverpool Royal Infirmary were 
Table 4. Distribution of resistance in serotypes $6,9,14,19,23$ and other types $(\mathrm{N})$

\begin{tabular}{|c|c|c|c|c|c|c|c|}
\hline \multirow{2}{*}{$\begin{array}{l}\text { Antibiotic } \\
\text { resistance }\end{array}$} & \multicolumn{6}{|c|}{ Serotype } & \multirow[b]{2}{*}{ Total } \\
\hline & 6 & 9 & 14 & 19 & 23 & $\mathrm{~N}$ & \\
\hline Pen & 10 & 30 & 15 & 16 & 12 & 26 & 109 \\
\hline Tet & 12 & 3 & 17 & 13 & 2 & 69 & 116 \\
\hline Eryth & 10 & 3 & 145 & 4 & 1 & 16 & 179 \\
\hline Chlor & 2 & 0 & 2 & 0 & 1 & 6 & 11 \\
\hline Pen/Tet & 5 & 2 & 7 & 4 & 3 & 9 & 30 \\
\hline Pen/Eryth & 0 & 0 & 3 & 3 & 1 & 1 & 8 \\
\hline Pen/Chlor & 1 & 0 & 1 & 1 & 8 & 2 & 13 \\
\hline Eryth/Tet & 8 & 0 & 2 & 2 & 3 & 3 & 18 \\
\hline Eryth/Chlor & 0 & 0 & 1 & 0 & 0 & 2 & 3 \\
\hline Chlor/Tet & 3 & 0 & 1 & 4 & 1 & 25 & 34 \\
\hline Pen/Chlor/Tet & 16 & 0 & 1 & 4 & 135 & 6 & 162 \\
\hline Pen/Eryth/Tet & 12 & 0 & 1 & 2 & 2 & 2 & 19 \\
\hline Pen/Chlor/Eryth & 0 & 0 & 0 & 1 & 0 & 0 & 1 \\
\hline Eryth/Chlor/Tet & 4 & 0 & 0 & 2 & 0 & 10 & 16 \\
\hline Pen/Chlor/Tet/Eryth & 42 & 0 & 2 & 0 & 5 & 0 & 49 \\
\hline Total & 125 & 38 & 198 & 56 & 174 & 177 & 768 \\
\hline
\end{tabular}

Pen, Penicillin; Tet, tetracycline; Eryth, erythromycin; Chlor, chloramphenicol. Bold type indicates the most common pattern in this serotype.

resistant to the drug [62]. In 1975 the proportion of tetracyline-resistant pneumococci ranged from $3 \%$ to $37 \%$ depending on the hospital [63], but then fell [64].

Erythromycin. Erythromycin is often used by family doctors for the empirical treatment of communityacquired pneumonia because it is active against mycoplasmas as well as pneumococci. Cross-resistance to lincomycin was found in the first isolates of erythromycin-resistant pneumococci [18].

From 1986, there was a striking increase in the number of referred pneumococci that were resistant to erythromycin. Of the total of 179 such isolates, 145 were of serotype 14 (Table 4). In the nine years 1982-1990, the sequence of erythromycin-resistant isolates of type 14 was: $1,0,1,0,8,16,31,37$ and 51. One erythromycin-resistant isolate of type 1 was isolated from pleural fluid 10 days after a susceptible isolates, also of type 1, had been found in blood cultures of that patient.

Elsewhere different patterns prevailed. In Belgium, for example, erythromycin-resistant isolates of type 6 were prevalent and most of these were resistant also to tetracycline [65]. There is some evidence of a linkage of genes for resistance to erythromycin and tetracycline, because co-transfer occurs in transformation tests [66]. Among our isolates of type 6, 10 were resistant to erythromycin alone and eight to both drugs (Table 4).

Penicillin. The 109 isolates that were insusceptible to penicillin alone were distributed among 19 serotypes, but $83(76 \%)$ belonged to one or other of the five serotypes $6,9,14,19$ or 23 . The screening tests used would not have been distinguished pneumococci that were insusceptible (MIC $0.1-1.0 \mathrm{mg} / \mathrm{L}$ ) or resistant
(MIC $\geqslant 2 \mathrm{mg} / \mathrm{L}$ ) to penicillin. More detailed studies of isolates were carried out by the Antibiotic Reference Unit [67].

Usually when a zone size of $<15 \mathrm{~mm}$ was found around an oxacillin disk $(1 \mu \mathrm{g})$ then the zone size about the benzylpenicillin disk $(0.6 \mu \mathrm{g})$ was $<25 \mathrm{~mm}$. However, there were exceptions. In 1982, for example, an isolate of type 6 from sputum exhibited zones of inhibition of $9 \mathrm{~mm}$ to oxacillin and $29 \mathrm{~mm}$ to penicillin. In restrospect these cultures may have been comparable to the recently described intermediately oxacillin-resistant pneumococci [68].

Multi-resistance. Multi-resistance, to penicillin, chloramphenicol and tetracycline, or penicillin, chloramphenicol, tetracycline and erythromycin, was prominent from 1985 onwards. Most isolates with the former pattern belonged to type 23 and selected isolates referred to the State Serum Institute, Copenhagen (Dr J. Henrichsen) were all found to be type 23F. The numbers of such isolates of type 23 for the years 1982-1990 were $1,1,2,8,18,28,22,22$ and 33. In 1986 , for the first time, cultures resistant to all four antibiotics were handled. In that year there were two of these cultures, one of type 6 , the other type 23 . In later years there were 2, 4, 10 and 25 isolates of type 6 and a total of four isolates of type 23 .

In 1990 there were 85 multi-resistant isolates, $9 \%$ of the total of 905 isolates for that year. This figure is higher than the nine $(1.7 \%)$ multi-resistant isolates found in 1990 among 530 cultures from 52 British laboratories [22]. This sample was composed of all pneumococci isolated over a 2 -week period.

The base sequence of the gene coding for the penicillin-binding protein $2 \mathrm{~B}$ was available for three 
of the type 23 isolates resistant to pencillin, chloramphenicol and tetracycline [69]. The sequences were the same as two type 23 strains from Spain. All could be distinguished from strains of other serotypes isolated, for instance in Papua-New Guinea or Africa, or a type 19 strain isolated in the UK.

Sources. The proportion of isolates that were insusceptible to antibiotics differed by source as well as serotype. Of the 581 cultures from sputum or nasal swabs (Table 1), $336(58 \%)$ were insusceptible to one or more agent. In contrast, of the 4238 isolates from patients with pneumonia, meningitis or bacteraemia $331(8 \%)$ were insusceptible. Among the isolates of type 23, 104 of the 135 cultures insusceptible to penicillin, chloramphenicol and tetracycline were isolated from sputum or nasal swabs, 15 from pneumonia, meningitis or bacteraemia, 10 from sporadic cases of conjunctivitis in babies and six from other sources. Such strains have spread within hospitals [70]. Of the total of 255 isolates of type 23 from cases of pneumonia, meningitis or bacteraemia, 23 $(9 \%)$ were insusceptible to one or more antibiotic. A greater proportion of insusceptible isolates of type 14 were from the same three conditions: 149 (29\%) of 630 cultures. Most were insusceptible to erythromycin alone.

During the period of this study there was an increase in the number of antibiotic-resistant pneumococci and this worrying trend continues [22]. The association of types 9 and 19 with insusceptibility to penicillin, type 14 with erythromycin resistance and types 6 and 23 with multi-resistance suggests the possibility of nationwide spread of a few resistant strains. It may be significant that representatives of these serotypes often caused invasive disease in children. Apart from the need to continue surveillance by reference laboratories there is a need for more general research. Possible areas include continuation of studies on microbial pathogenicity [71]; development of new vaccines, including conjugated preparations; the definition of groups that would, or would not, benefit from immunisation and the development of additional methods for the diagnostic laboratory, such as an enzyme test to replace the bile solubility test.

We thank our colleagues in hospital and public health laboratories for referring isolates for typing and supplying clinical information.

\section{References}

1. Henrichsen J. Six newly recognized types of Streptococcus pneumoniae. J Clin Microbiol 1995; 33: 2759-2762.

2. Venkateswaran PS, Stanton N, Austrian R. Type variation of strains of Streptococcus pneumoniae in capsular serogroup 15. J Infect Dis 1983; 147: 1041-1054.

3. Hodges RG, MacLeod CM. Epidemic pneumococcal pneumonia. I. Description of the epidemic. Am J Hyg 1946; 44: 183192.

4. Aszkenasy ON, George RC, Begg NT. Pneumococcal bacteraemia and meningitis in England and Wales 1982 to 1992. Commun Dis Rep CDR Rev 1995; 5: R45-R50.

5. Lund E. Types of pneumococci found in blood, spinal fluid and pleural exudate during a period of 15 years (1954-1969). Acta
Path Microbiol Scand B Microbiol Immunol 1970; 78: 333336.

6. Nielsen SV, Henrichsen J. Capsular types and susceptibility to penicillin of pneumococci isolated from cerebrospinal fluid or blood in Denmark, 1983-1988. Scand J Infect Dis 1993; 25: $165-170$.

7. Klugman KP, Koornhof HJ. Drug resistance patterns and serogroups or serotypes of pneumococcal isolates from cerebrospinal fluid or blood, 1979-1986. J Infect Dis 1988; 158: $956-964$.

8. Greenwood BM, Hassan-King M, MacFarlane JT et al. Pneumococcal serotypes in West Africa. Lancet 1980; 1: 360.

9. Austrian R. Untreated pneumococcal bacteraemia of cryptic origin in the human adult with spontaneous recovery. $S$ Afr Med $J$ 1986; October 11; Supplement: S46-S49.

10. Riley ID, Douglas RM. An epidemiologic approach to pneumococcal disease. Rev Infect Dis 1981; 3: 233-245.

11. Hansman D. Serotypes in pneumococcal disease. A ten year study in Australia 1970 through 1979. Aust NZ J Med 1983; 13: $359-364$

12. Orange M, Gray BM. Pneumococcal serotypes causing disease in children in Alabama. Pediatr Infect Dis $J$ 1993; 12: $244-$ 246 .

13. Klugman KP. Pneumococcal resistance to antibiotics. Clin Microbiol Rev 1990; 3: 171-196.

14. Abraham EP, Chain E, Fletcher CM et al. Further observations on penicillin. Lancet 1941; 2: 177-189.

15. Watson DA, Musher DM, Jacobson JW, Verhoef J. A brief history of the pneumococcus in biomedical research: a panoply of scientific discovery. Clin Infect Dis 1993; 17: 913-924.

16. Evans W, Hansman D. Tetracycline-resistant pneumococcus. Lancet 1963; 1 : 451.

17. Hansman D, Bullen MM. A resistant pneumococcus. Lancet 1967; 2: 264-265.

18. Dixon JMS. Pneumococcus resistant to erythromycin and lincomycin. Lancet 1967; 1: 573.

19. Cybulska J, Jeljaszewicz J, Lund E, Munksgaard A. Prevalence of types of Diplococcus pneumoniae and their susceptibility to 30 antibiotics. Chemotherapy 1970; 15: 304-316.

20. Jacobs MR, Koornhof HJ, Robins-Browne RM et al., Emergence of multiply resistant pneumococci. $N$ Engl J Med 1978; 299: 735-740.

21. Colman G, Hallas G. Systemic disease caused by pneumococci. J Infect 1983; 7: 248-255.

22. Johnson AP, Speller DCE, George RC, Warner M, Domingue G, Efstratiou A. Prevalence of antibiotic resistance and serotypes in pneumococci in England and Wales: results of observational surveys in 1990 and 1995. BMJ 1996; 312: 1454-1456.

23. Lund E. Diagnosis of pneumococci by the optochin and bile tests. Acta Path Microbiol Scand 1959; 47: 308-315.

24. Colman G. The classification of streptococcal strains. PhD thesis, University of London. 1970: 312.

25. Austrian R, Buettger C, Dole M. Problems in the classification and pathogenic role of alpha and nonhemolytic streptococci of the human respiratory tract. In: Wannamaker LW, Matsen JM (eds) Streptococci and streptococcal diseases: recognition, understanding, and management. New York, Academic Press. 1972: 355-370.

26. Kauffmann F, Lund E, Eddy BE. Proposal for a change in the nomenclature of Diplococcus pneumoniae and a comparison of the Danish and American type designations. Int Bull Bacteriol Nomen Taxon 1960; 10: 31-40.

27. Smart LE. Serotyping of Streptococcus pneumoniae strains by coagglutination. J Clin Pathol 1986; 39: 328-331.

28. Lund E, Henrichsen J. Laboratory diagnosis, serology and epidemiology of Streptococcus pneumoniae. In: Bergan $\mathrm{T}$, Norris JR (eds) Methods in microbiology, Vol 12. London, Academic Press. 1978: 241-262.

29. Snell JJS, George RC, Perry SF, Erdman YJ. Antimicrobial susceptibility testing of Streptococcus pneumoniae: quality assessment results. J Clin Pathol 1988; 41: 384-387.

30. Dixon JMS, Lipinski AE, Graham MEP. Detection and prevalence of pneumococci with increased resistance to penicillin. Can Med Assoc J 1977; 117: 1159-1161.

31. Hansman D, Morris S. Pneumococcal carriage amongst children in Adelaide, South Australia. Epidemiol Infect 1988; 101: $411-417$.

32. Scott JAG, Hall AJ, Dagan $\mathrm{R}$ et al. Serogroup-specific 
epidemiology of Streptococcus pneumoniae: assocations with age, sex, and geography in 7,000 episodes of invasive disease. Clin Infect Dis 1996; 22: 973-981.

33. Taunay AE, Austrian R, Landgraf IM, Vieira MFP, Melles CEA. Sorotipos de Streptococcus pneumoniae isolados de líquido cefalorraquidiano no período de 1977-1988 na cidade de São Paulo, Brasil. [Serotypes of Streptococcus pneumoniae isolated from cerebrospinal fluid in 1977-1988 in Sao Paulo City, Brazil]. Rev Inst Med Trop São Paulo 1990; 32: 11-15.

34. Gratten M, Morey F, Dixon J et al. An outbreak of serotype 1 Streptococcus pneumoniae infection in central Australia. Med $J$ Aust 1993; 158: 340-342.

35. Janoff EN, Breiman RF, Daley CL, Hopewell PC. Pneumococcal disease during HIV infection. Epidemiologic, clinical, and immunologic perspectives. Ann Int Med 1992; 117: 314324.

36. Bratton L, Teele DW, Klein JO. Outcome of unsuspected pneumococcemia in children not initially admitted to hospital. $J$ Pediatr 1977; 90: 703-706.

37. Gruer LD, McKendrick MW, Geddes AM. Pneumonococcal bacteraemia - a continuing challenge. $Q \mathrm{~J} \mathrm{Med} \mathrm{1984;} \mathrm{53:}$ 259-270.

38. Walker W. Splenectomy in childhood: a review in England and Wales, 1960-4. Br J Surg 1976; 63: 36-43.

39. Gaston MH, Verter JI, Woods G et al. Prophylaxis with oral pencillin in children with sickle cell anemia. A randomized trial. $N$ Engl J Med 1986; 314: 1593-1599.

40. Turk DC. Frequencies of pneumonoccal types causing serious infections in patients admitted to the Radcliffe Infirmary, Oxford, 1969-77. J Hyg 1978; 81: 227-238.

41. Lund E. Distribution of age and sex in cases of pneumococcal meningitis. Acta Path Microbiol Scand 1964; 61: 487-490.

42. Smit P, Oberholzer D, Hayden-Smith S, Koornhof HJ, Hilleman MR. Protective efficacy of pneumococcal polysaccharide vaccines. JAMA 1977; 238: 2613-2616.

43. Butler JC, Breiman RF, Campbell JF, Lipman HB, Broome CV, Facklam RR. Pneumococcal polysaccharide vaccine efficacy. An evaluation of current recommendations. JAMA 1993; 270: 1826-1831.

44. John AB, Ramlal A, Jackson H, Maude GH, Waight Sharma A, Serjeant GR. Prevention of pneumococcal infection in children with homozygous sickle cell disease. $B M J 1984 ; 288$ : 1567-1570.

45. Nelson JD, Scheetz MD (eds). Proceedings of a workshop on vaccines for otitis media. Pediatr Infect Dis J 1989; 8 Suppl: $\mathrm{S} 1-\mathrm{S} 97$.

46. Jacobs NM. Pneumococcal osteomyelitis and arthritis in children. A hospital series and literature review. Am $J$ Dis Child 1991; 145: 70-74.

47. Denis F, Mounier M, Descottes B, Cubertafond P, Catanzano G. Abdominal infections caused by Streptococcus pneumoniae. Eur J Clin Microbiol 1984; 3: 443.

48. McFarlane AC, Hamra LK, Reiss-Levy E, Hansman D. Pneumococcal peritonitis in adolescent girls. Med $J$ Aust 1979; 1: 100-101.

49. Gruer LD, Collingham KE, Edwards CW. Pneumonococcal peritonitis associated with an IUCD. Lancet 1983; 2: 677.

50. McCartney JE. The pathogenesis of primary pneumococcal peritonitis. J Pathol Bacteriol 1923; 26: 507-517.

51. Austrian R, Gold J. Pneumococcal bacteremia with especial reference to bacteremic pneumococcal pneumonia. Ann Int Med 1964; 60: 759-776.

52. Bergqvist G, Trovik M. Neonatal infections with Streptococcus pneumoniae. Scand $J$ Infect Dis 1985; 17: 33-35.

53. Primhak RA, Tanner MS, Spencer RC. Pneumococcal infection in the newborn. Arch Dis Child 1993; 69: 317-318.

54. Shayegani M, Parsons LM, Gibbons WE, Campbell D. Characterization of nontypable Streptococcus pneumoniae-like organisms isolated from outbreaks of conjunctivitis. $J$ Clin Micrbiol 1982; 16: 8-14.

55. Finland M, Barnes MW. Changes in occurrence of capsular serotypes of Streptococcus pneumoniae at Boston City Hospital during selected years between 1935 and 1974. $J$ Clin Microbiol 1977; 5: 154-166.

56. Smart LE, Dougall AJ, Girdwood RWA. New 23-valent pneumococcal vaccine in relation to pneumococcal serotypes in systemic and non-systemic disease. J Infect 1987; 14: 209215.

57. Bridges-Webb C, Dunstone MW. The Australian general practice morbidity and prescribing survey 1969 to 1974: respiratory infections. Med $J$ Aust 1976; 2 Special Suppl 1: $18-20$

58. Smart LE, Platt DJ, Timbury MC. A comparison of the distribution of pneumococcal types in systemic disease and the upper respiratory tract in adults and children. Epidemiol Infect 1987; 98: 203-209.

59. Ward J, Koornhof H. Antibiotic-resistant pneumococci. In: Remington JS, Swartz MN (eds) Current clinical topics in infectious diseases, Vol 1. New York, McGraw-Hill Book Company. 1980: 265-287

60. Kontiainen S, Sivonen A. Optochin resistance in Streptococcus pneumoniae strains isolated from blood and middle ear fluid. Eur J Clin Microbiol 1987; 6: 422-424.

61. Turner GC. Tetracycline-resistant pneumococci in a general hospital. Lancet 1963; 2: 1292-1295.

62. Percival A, Armstrong EC, Turner GC. Increased incidence of tetracycline-resistant pneumococci in Liverpool in 1968. Lancet 1969; 1: 998-1000.

63. Kensit J, Farrell W, Evans S et al. Tetracycline resistance in pneumococci and group A streptococci. Report of an ad-hoc study group on antibiotic resistance. BMJ 1977; 1: 131-133.

64. Howard AJ, Hince CJ, Williams JD. Antibiotic resistance in Streptococcus pneumoniae and Haemophilus influenzae. Report of a study group on bacterial resistance. BMJ 1978; 1: 16571660.

65. Verhaegen J, Goubau P, Verbist L, Glupczynski J, Blogie M, Yourassowsky E. Erythromycin-resistant Streptococcus pneumoniae. Lancet 1988; 2: 1432-1433.

66. Young FE, Mayer L. Genetic determinants of microbiol resistance to antibiotics. Rev Infect Dis 1979; 1: 55-63.

67. George RC, Ball LC, Cooper PG. Antibiotic-resistant pneumococci in the United Kingdom. Commun Dis Rep CDR Rev 1992; 2: R37-R43.

68. Dowson CG, Johnson AP, Cercenado E, George RC. Genetics of oxacillin resistance in clinical isolates of Streptococcus pneumoniae that are oxacillin resistant and penicillin susceptible. Antimicrob Agents Chemother 1994; 38: 49-53.

69. Dowson CG, Hutchison A, Brannigan JA et al. Horizontal transfer of penicillin-binding protein genes in pencillin-resistant clinical isolates of Streptococcus pneumoniae. Proc Natl Acad Sci USA 1989; 86: 8842-8846.

70. Pallett AP, Strangeways JEM. Penicillin-resistant pneumococci. Lancet 1988; 1: 1452 .

71. Boulnois GJ. Pneumococcal proteins and the pathogenesis of disease caused by Streptococcus pneumoniae. J Gen Microbiol 1992; 138: 249-259. 